\title{
PSYCHE.
}

ORGAN OF THE CAMBRIDGE ENTOMOLOGICAL CLUB EDITED BY B. PICKMAN MANN.

Vol. I.] Cambridge, Mass., November, 1876. [No. 31.

\section{Synoptical Tables for determining N. A. Insects. Scorpiones.}

In the Annals and Mag. Nat. Hist., ser. 4, vol. xvii, p. 1-15 (Jan. 1876), Prof. T. Thorell has published an essay on the classification of Scorpions [see Rec., No. 619], from which the following synopsis of genera is adapted. The synopsis is prefaced by the following scheme of the orders in the class Arachnoidea, indicating the relative position of each.

Class Arachnoidea.

Subcl. 1. Thoracopoda Thor.

Ord. 1. Scorpiones.

Ord. 2. Pedipalpi. Ord. 3. Araneae.

Ord. 6. Pseudoscorpiones. Ord. 4. Opiliones.

Ord. 7. Acari.

Ord. 8. Linguatulina ( $=$ fam. Pentastomoidae).

Subcl. 2. (Ord. 9.) Cormopona Thor. (= fam. Artiscoidae).

1 (18) Sternum narrowing forwards, subtriangular. [Intermediate plates of the pectoral combs ${ }^{1}$ rather few in number, most of them angular and larger than the fulcra, and forming only one series. The movable finger of the mandibles (which always forms a perfect fork) has two rows of teeth; the immovable finger has two teeth in the upper margin, 2-0 in the under. The fingers of the palpi are provided with a number of oblique rows of fine teeth, along the middle of their

1 The plates of the front row are called dorsal plates; those of the hind row, each supporting a tooth of the comb, are the fulcra; those between are the intermediate plates. 
edge, and with other, generally coarser teeth, arranged in one or more rows on each side of these. Three principal lateral eyes and 2-0 accessory eyes on each side of the cephalothorax.]

Fam. I. Androctonoidae.

2 (5) Not only the upper but also the under margin of the immovable mandibular finger armed with two strong teeth. [Lateral teeth of the palp-fingers, which are coarser than the median teeth, forming along the inner side a single simple row, but arranged along the outer side in a series of teeth placed two and two obliquely and transversely near to each other. No tooth or spine under the base of the sting. Generally two accessory eyes, besides the three principal eyes, on each side of the cephalothorax.] . . . . . Subfam. 1. Androctoninr.

3 (4) The fifth joint of the tail broadly excavated above, its upper margins forming an elevated denticulate or granulate keel . Androctonus.

4 (3) The upper margins of the fifth joint of the tail rounded, not compressed into an elevated keel . . . . . . . . . Buthus.

5 (2) The under margin of the immovable mandibular finger has no tooth or only one. [Lateral teeth of the palp-fingers arranged in a single row or forming several short transverse rows. The sixth joint of the tail generally provided with a spine or tooth under the sting. Accessory lateral eyes often wanting, sometimes one or two on each side.]

Subfam. 2. Centrurini.

6 (7) "Joints of the tail destitute of keels." . . . . . Uroplectes.

7 (6) At least a few of the joints of the tail evidently keeled.

8 (11) Under margin of the immovable mandibular finger toothless.

9 (10) Lateral teeth of the palp-fingers forming on the inner side a single simple row, but arranged on the outer side in a row which partly consists of teeth placed two and two transversely near to each other.

10 (9) Lateral teeth of the palp-fingers forming, both on the inner and outer side, a row of teeth placed two and two transversely near to each other . . . . . . . . . . . . . . . . . . Tityus.

11 (8) Under margin of the immovable mandibular finger armed with one (very small) tooth.

12 (15) Both the inner and outer lateral teeth of the palp-fingers arranged in a single row.

13 (14) The fifth joint of the tail broadly excavated above, its upper margins forming an elevated keel . . . . . . . Phassus.

14 (13) Upper margins of the fifth joint of the tail rounded, not forming an elevated keel . . . . . . . . . . . . . . Isometrus.

15 (12) Both the inner and outer lateral teeth of the palp-fingers arranged in a number of short oblique rows, with at least three teeth in each row.

${ }^{1}$ Peters, the author of the genus, has placed in it a species with "upper crests of the tail distinct." Uroplectes is perhaps not different from Tity us. 
16 (17) The fifth joint of the tail broadly excavated above, its upper margins forming an elevated keel . . . . . . . Rhopalurus.

17 (16) The upper margins of the fifth joint of the tail rounded, not forming an elevated keel . . . . . . . . . Centrurus.

18 (1) Sternum either very short, forming a transverse falciform band or line, or else with parallel sides and subpentagonal.

19 (24) Sternum very short, forming a transverse falciform band or line curved backwards between the coxæ of the second pair of legs and the genital plates. [Intermediate plates of the combs generally (always?) numerous, most of them rounded and small (little or no larger than the fulcra), and arranged in 1-3 longitudinal rows. Both fingers of the mandibles provided with a single row of teeth. Lateral eyes three or two (?) on each side, small. No tooth or spine under the sting.] . . . . . . . . . . . Fam. II. Telegonoidae.

20 (23) Tail without keels on the underside.

21 (22) The fifth joint of the tail provided on the underside, near the apex, with a large, depressed, almost semi-elliptical area, rounded in front, and limited by a row of small teeth or granules . Bothriurus.

22 (21) The fifth joint of the tail smooth below, without a depressed semi-elliptical area . . . . . . . . . . . Telegonus.

23 (20) Tail keeled at least on the under side of the fifth joint.

Cercophonius.

24 (19) Sternum with parallel sides, subpentagonal. [The movable mandibular finger provided with one or two rows, the immovable with a single row of teeth.]

25 (28) Sternum rather small, about double as broad as long. Intermediate plates of the combs generally (always?) numerous, most of them rounded and small (little or no larger than the fulcra), and arranged in 1-3 longitudinal rows. The hands subfusiform or ovate, their height or thickness in general greater than their least breadth. [Three (or four) lateral eyes on each side, forming a row curved inwards. ${ }^{1}$ No spine or tooth under the sting.] . . . . Fam. III. Vejovoidae.

26 (27) The movable mandibular finger provided with a single row of teeth in the upper margin. Dorsal eyes placed rather far in front ${ }^{2}$ of the centre of cephalothorax . . . . . . . . . Vejovis.

27 (26) The movable mandibular finger not only provided with a row of teeth in the upper margin, but also with a tooth in the under margin. Dorsal eyes not far removed from the centre of cephalothorax.

Hadrurus.

$\mathbf{1}$ According to Peters, these scorpions have two principal lateral eyes and one or two accessory eyes.

${ }^{2}$ The measures are taken from the eyes to a straight line tangent to the anterior margins of the frontal lobes, and to the middle of the posterior margin of the cephalothorax. 
28 (25) Sternum generally large. Intermediate plates of the combs rather few in number, angular, and (at least most of them) larger than the fulcra, and arranged in a single row. Hands broader than high, in general large and depressed. [Principal lateral eyes three or two; accessory eyes in general wanting, rarely one on each side. Sixth joint of the tail nearly always destitute of a tooth or spine under the sting.] . . . . . . . . . . Fam. IV. Pandinoidae.

29 (32) The movable mandibular finger not only provided with a row of teeth in the upper, but also with one or more teeth in the under margin. [Cephalothorax emarginate in front; dorsal eyes situated far in front of the centre of cephalothorax; lateral eyes three, removed from the lateral margin of cephalothorax. Sternum as broad as the labial lobes of the second pair of legs together. Hands rather large, thick; the hand-back ${ }^{1}$ forming an obtuse angle with the upper surface of the hand. Tail evidently keeled, its sixth joint long, not grooved on the under side.] . . . . . . . . . . . . Subfam. 1. Iurini.

30 (31) The under margin of the movable mandibular finger armed with one strong tooth. The fine teeth along the middle of the edge of the palp-fingers forming many short oblique rows . . . . . Iurus.

31 (30) The under margin of the movable mandibular finger provided with a row of (5) teeth. The teeth along the middle of the edge of the palp-fingers forming a single continuous row . . Uroctonus.

32 (29) The movable mandibular finger provided with a single row of teeth, situated in its upper margin . . . Subfam. 2. Pandinini.

33 (52) Three principal lateral eyes on each side.

34 (35) "Joints of the tail rounded, without keels." 2 . . Dacurus.

35 (34) Tail evidently keeled.

36 (37) "A spine under the base of the sting." . . . . Diplocentrus.

37 (36) No tooth or spine under the sting.

38 (47) Lateral eyes removed from the lateral margin of cephalothorax. Hand-back forming an acute angle with the upper side of the hand.

39 (46) Dorsal eyes not very far removed from the centre of cephalothorax. Under side of tail provided with three longitudinal grooves, and with granules arranged in at least four longitudinal rows. Iabial lobes of second pair of legs together from half as broad again to double as broad as sternum.

40 (41) Cubitus rounded off anteriorly; its anterior side not separated by a strong margin or ridge from the upper and under surfaces.

Heterometrus.

1 The hand-back is that surface of the hand which (in the family Pandinoidae) is turned outwards, and which is bounded by the two strongest costæ of the hand.

2According to Peters; C. L. Koch, however, says of his "Centrurus" [Dacurus] galbineus: "The lateral keels and the inferior keels indeed present, but not very strongly developed." The hands are said to be "narrow, uneven on the outside, without distinct keels" Koch gives this species ten eyes (?) 
41 (40) Cubitus subprismatic, with the anterior and superior sides plain; anterior side subrectangular, limited both above and below by a very distinct dentate or granulate margin.

42 (45) Anterior margin of cephalothorax rather broadly and deeply emarginate, its frontal lobes rounded.

43 (44) Inner margin of the hands strongly compressed, thin. Dorsal eyes situated a little behind the centre of cephalothorax - Pandinus.

44 (43) Inner margin of the hands very thick, not compressed. Dorsal eyes situated a little in front of the centre of cephalothorax.

Palamnaeus.

45 (42) Anterior margin of cephalothorax rather slightly emarginate in the middle; frontal lobes broadly truncate . . . . . Miaephonus.

46 (39) Dorsal eyes situated about double as far from the anterior margin of cephalothorax as from its posterior margin. The sixth joint of the tail destitute of rows of granules and of distinct grooves on the under side. Labial lobes of second pair of legs together a little broader than (not more than half as broad again as) sternum. Opisthophthalmus.

47 (38) Lateral eyes, at least the anterior one, situated very near to or on the lateral margin of cephalothorax. Hand-back forming an obtuse or nearly right angle with the upper side of the hand.

48 (51) Tail not much compressed; its superior margins not keeled.

49 (50) The elevated lateral margin of cephalothorax visible under the lateral eyes; these eyes, therefore, separated from the margin by a slight interval. Hands not much flattened . . . Opisthacanthus.

50 (49) Lateral eyes situated on the very margin of cephalothorax. Hands very flat . . . . . . . . . . . Hormurus.

51 (48) Tail rather strongly compressed, with keels both on the upper and under side . . . . . . . . . . . . . . . Ischnurus. ${ }^{1}$

52 (33) Two principal lateral eyes on each side. ${ }^{2}$

53 (54) "Tail with only three keels on the under side, thick, its keels strong." . . . . . . . . . . . . . . . . . Urodacus.

54 (53) The first four joints of the tail with four keels on the under side.

55 (56) Sternum narrower than the labial lobes of the second pair of legs together . . . . . . . . . . . . . . . . Broteas.

56 (55) Sternum as broad as the labial lobes of the second pair of legs together.

1 The place of Hemiscorpius is probably in the vicinity of this genus. It is characterized by Peters in the following words: - "Sternum as broad as the labial lobes of the second pair. Frontal margin scarcely emarginate. Body and extremities flattened. Tail slender, long, higher than broad, keeled, its sixth joint with two lateral tubercles (in the males) behind the base of the short sting. The hind lateral eye somewhat smaller, placed more inwards." If the tubercles mentioned by Peters also exist in the females, Hemiscorpius is without doubt a good genus.

2 There is sometimes an accessory eye on one or both sides of cephalothorax, or the hind lateral eye is divided into two. 
57 (58) "Sternum longer than broad. Hands flat, angular." . Scorpiops.

58 (57) Sternum broader than long. Hand-back forming, with the upperside of the hand, a right or obtuse angle.

59 (60) Dorsal eyes situated nearly in the middle of cephalothorax, which is emarginate in front; dorsal eye-tubercle divided by a longitudinal middle groove. Hands rather thick. Tail somewhat strong, with strongly marked keels on all sides . . . . . . . . . Ioctonus.

60 (59) Dorsal eyes far in front of the centre of cephalothorax; frontal margin not, or but little, emarginate; dorsal eye-tubercle destitute of a longitudinal middle groove. Hands flattened. Tail slender.

Euscorpius.

Some of the genera are more fully defined, and the names of their authors and of the typical species, and the dates of their establishment, are given in the work from which this is derived.

B. Pickman Mann.

\section{BIBLIOGRAPHICAL RECORD.}

Authors and Societies are requested to forward their works to the Editor at the earliest date possible. We ask our readers to inform us of the publication especially of those works which are not generally consulted by entomologists.

B. Pickman Mann.

(Continued from page 208.)

Psyche, vol. i, contains Nos. 641 to 715 .

* 641. B. P. ManN. Introductory. p. 1-2.

* 642. S. H. Scuddkr. English Names for Butterflies. pp. 2-3, 10-11, 31, 40, 43-44, 56 .

* 643. B. P. Mann. Bibliographical Record. pp. 3-4, 7-8, 11-12, 15-16, 19-20, 23-24, 27-28, 31-32, 36-39, 44$48,52-56,59-64,70-72,78-80,86-88,94-96,100-104,107-$ 112, 115-120, 125-128, 132-136, 140-143, 148-151, 156-160, 163-167, 172-176, 179-183, 188-192, 195-200, 205-208, 214 $-216,217-218$.

* 644. H. K. Morrison. Interesting Capture. p. 4.

* 645. B. P. Mann. Hentz's Spiders. p. 4 [p. 24, footnote].

* 646. H. G. Hubbard. Notes on the Habits of Magdalinus armicollis Say. p. 5-6.

* 647. B. P. Mann. Entomological Excursion to Mt. Washington. p. 6 . 

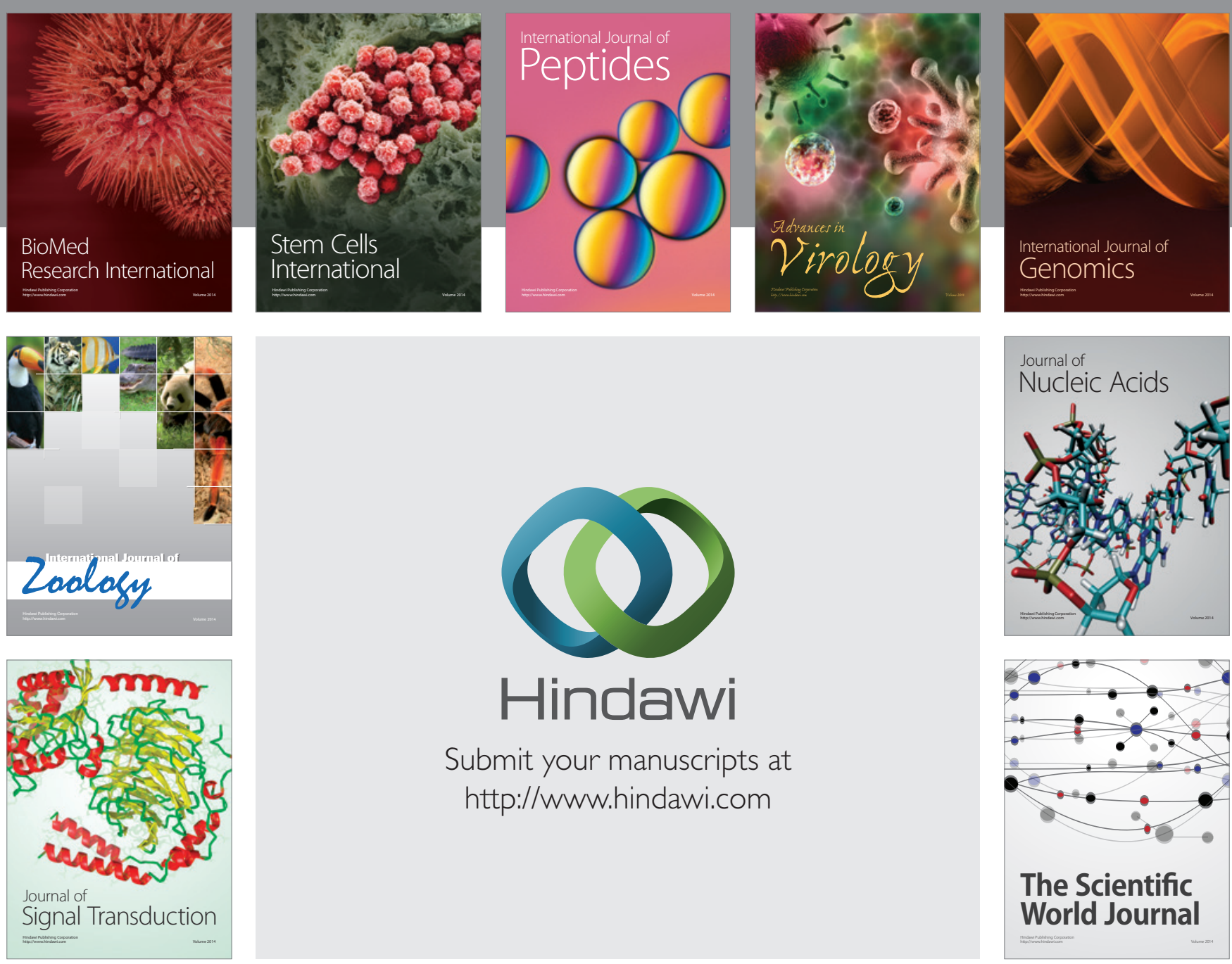

Submit your manuscripts at

http://www.hindawi.com
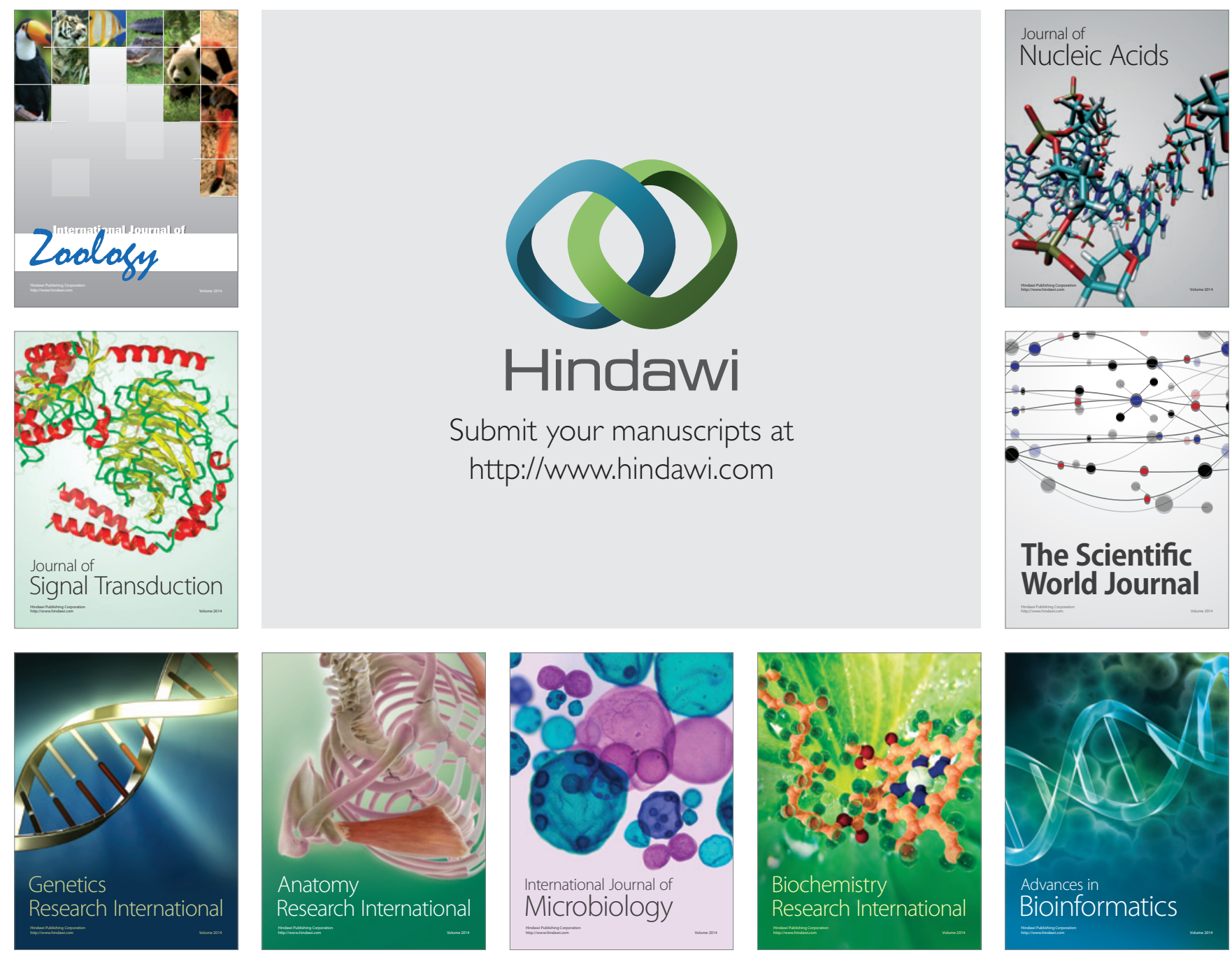

The Scientific World Journal
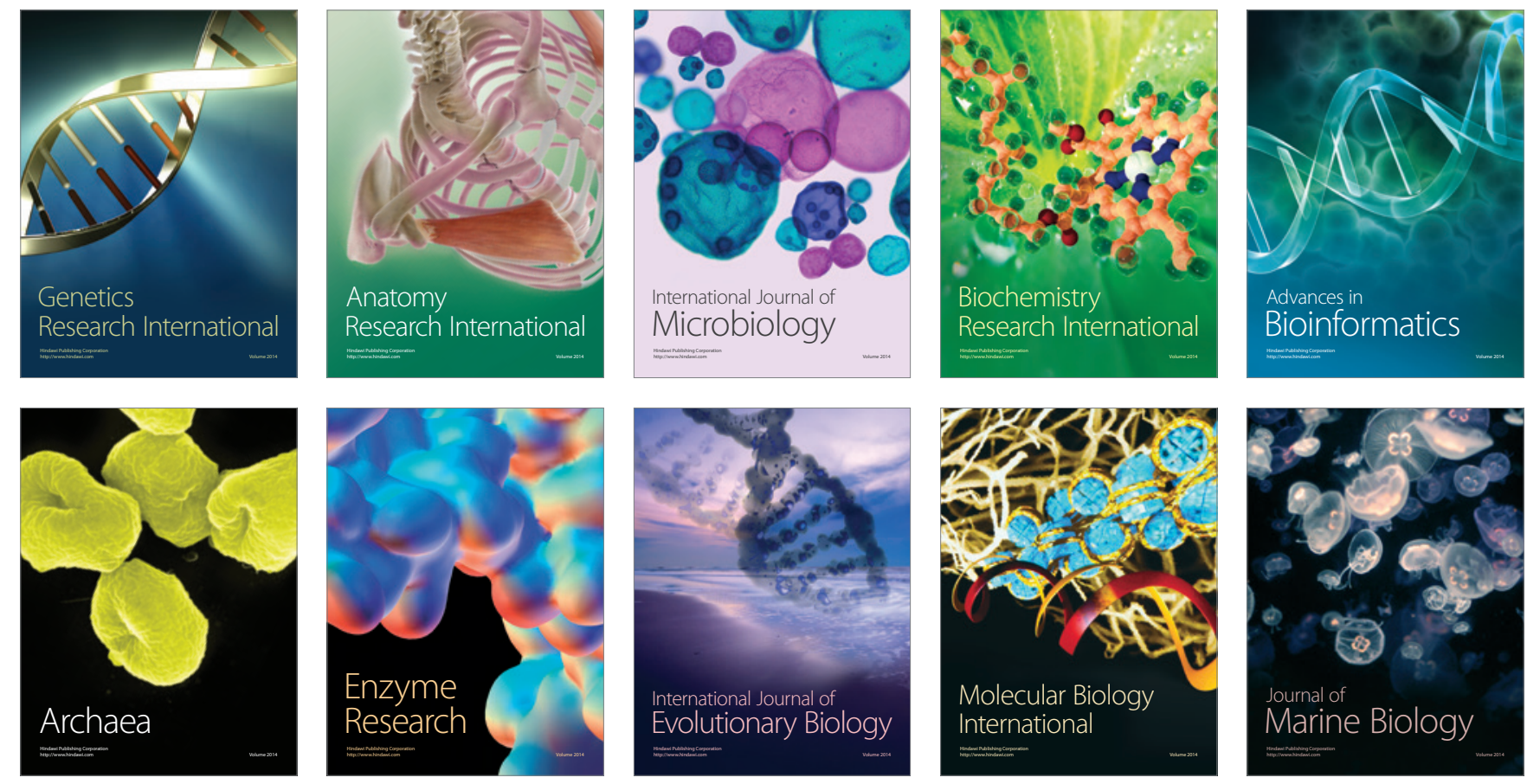